\title{
Article \\ A Link between Mitochondrial Dysregulation and Idiopathic Autism Spectrum Disorder (ASD): Alterations in Mitochondrial Respiratory Capacity and Membrane Potential
}

\author{
Hazirah Hassan (D), Fazaine Zakaria, Suzana Makpol (D) and Norwahidah Abdul Karim *(D) \\ Department of Biochemistry, Faculty of Medicine, Universiti Kebangsaan Malaysia, Kuala Lumpur 56000, \\ Malaysia; p90607@siswa.ukm.edu.my (H.H.); fazaine@yahoo.com.my (F.Z.); \\ suzanamakpol@ppukm.ukm.edu.my (S.M.) \\ * Correspondence: wahida2609@gmail.com
}

Citation: Hassan, H.; Zakaria, F.; Makpol, S.; Karim, N.A. A Link between Mitochondrial

Dysregulation and Idiopathic Autism Spectrum Disorder (ASD): Alterations in Mitochondrial Respiratory Capacity and Membrane Potential. Curr. Issues Mol. Biol. 2021, 43, 2238-2252. https://doi.org/10.3390/ cimb43030157

Academic Editors: Cristina Angeloni and Andrea Tarozzi

Received: 28 October 2021

Accepted: 11 December 2021

Published: 16 December 2021

Publisher's Note: MDPI stays neutral with regard to jurisdictional claims in published maps and institutional affiliations.

Copyright: (c) 2021 by the authors. Licensee MDPI, Basel, Switzerland. This article is an open access article distributed under the terms and conditions of the Creative Commons Attribution (CC BY) license (https:/ / creativecommons.org/licenses/by/ $4.0 /)$.
Abstract: Autism spectrum disorder (ASD) is a neurological disorder triggered by various factors through complex mechanisms. Research has been done to elucidate the potential etiologic mechanisms in ASD, but no single cause has been confirmed. The involvement of oxidative stress is correlated with ASD and possibly affects mitochondrial function. This study aimed to elucidate the link between mitochondrial dysregulation and idiopathic ASD by focusing on mitochondrial respiratory capacity and membrane potential. Our findings showed that mitochondrial function in the energy metabolism pathway was significantly dysregulated in a lymphoblastoid cell line (LCL) derived from an autistic child (ALCL). Respiratory capacities of oxidative phosphorylation (OXPHOS), electron transfer of the Complex I and Complex II linked pathways, membrane potential, and Complex IV activity of the ALCL were analyzed and compared with control cell lines derived from a developmentally normal non-autistic sibling (NALCL). All experiments were performed using high-resolution respirometry. Respiratory capacities of OXPHOS, electron transfer of the Complex Iand Complex II-linked pathways, and Complex IV activity of the ALCL were significantly higher compared to healthy controls. Mitochondrial membrane potential was also significantly higher, measured in the Complex II-linked pathway during LEAK respiration and OXPHOS. These results indicate the abnormalities in mitochondrial respiratory control linking mitochondrial function with autism. Correlating mitochondrial dysfunction and autism is important for a better understanding of ASD pathogenesis in order to produce effective interventions.

Keywords: autism; mitochondria; mitochondrial respiration; high-resolution respirometry; oxidative phosphorylation; mitochondrial membrane potential

\section{Introduction}

Autism spectrum disorder (ASD) is a heterogeneous neurodevelopmental disorder characterized by a combination of impairments in social communication and interaction, sensory anomalies, repetitive behaviors, and varying levels of intellectual disability. The global prevalence of ASD has increased dramatically 20- to 30-fold over the past decades [1] and the World Health Organization estimated that 1 in 160 children is affected by ASD [2]. The recent increase in ASD underscores the importance of expanding research into risk factors and effective interventions. Whilst most studies focus on effective interventions on promoting communication, social skills, and education [3], the underlying cause of idiopathic autism remains unclear. Up to the present, no significant underlying cause and no pharmacological medication is currently established as a treatment. Tracking the increase in ASD prevalence poses unique challenges because of its complex nature, lack of diagnostic biomarkers, and challenging diagnostic criteria.

Over the last decade, increasing attention has been paid to the mitochondrial physiology that may underlie some of the symptoms of ASD. Often mitochondrial dysfunction 
$(\mathrm{mtD})$ is associated with the inability of mitochondria to transform the chemical energy in the form of ATP. mtD manifests as a change in mitochondrial structure, membrane potential, mitochondrial enzyme activity, and dysregulated mitochondrial energy metabolism, which is frequently linked to oxidative/nitrosative stress [4]. Reports showed that autism was correlated with increased oxidative stress that might subsequently trigger oxidative damages, which could be involved in the pathogenesis of the disorder [5]. $\mathrm{mtD}$ is also implicated with other neurodegenerative diseases, such as Alzheimer's disease, Huntington's disease and Parkinson's disease [6-9], and aging [10]. However, the factors that cause mtD are still unknown. Some studies suggest that $\mathrm{mtD}$ is a consequence of dysreactive immunity and altered calcium signaling [11], malnutrition and vitamin deficiencies, exposure to environmental toxicants, and oxidative stress [12-14].

At cellular and molecular levels, $\mathrm{mtD}$ results in many negative downstream consequences. These include reduced synaptic neurotransmitter release in neurons that have high firing rates, such as inhibitory $\gamma$-aminobutyric acid interneurons, which in turn could result in reduced inhibition of neurotransmitter release [15] and the relative increase in the excitatory-to-inhibitory ratio observed in ASD patients [16]. Mitochondria are concentrated in the dendritic and axonal termini where they play an important role in ATP production, calcium homeostasis, and synaptic plasticity [4], pointing toward a connection between $\mathrm{mtD}$ and ASD. Importantly, brain cells have a high aerobic energy demand. Thus, a dysregulation of pathways in mitochondrial energy metabolism (i.e., oxidative phosphorylation (OXPHOS) and ATP turnover) might be the underlying cause of ASD pathogenesis.

Biochemical diagnosis of $\mathrm{mtD}$ is frequently restricted to the measurement of lactate, pyruvate, and some amino acids in plasma, cerebrospinal fluid, and urine [4,17], whereas recent studies reveal the linkage between the electron transport chain and $\mathrm{mtD}$ [18]. Nevertheless, in our study, the mitochondrial function of lymphoblastoid cell lines (LCL) derived from an autistic child (ALCL) was investigated by the determination of cytochrome $c$ oxidase (CIV) activity, respiration of intact and permeabilized cells, and mitochondrial membrane potential (mtMP).

The mitochondrial function studied here involves electron transfer in an NADHlinked pathway (N-pathway), which is obtained by the addition of NADH-generating substrate combinations of pyruvate $(P)$, glutamate $(G)$, and malate $(M)$. This is linked to Complex I (CI). The electron transfer in a succinate-linked pathway (S-pathway) is obtained by the addition of succinate (S), which is the only substrate of Complex II (CII). Electron transfer from both pathways combines (NS-pathway) and converges at the Q-junction. The downstream electron flow is catalyzed by Complex III (CIII) and CIV. In the presence of fuel substrates and ADP, the OXPHOS capacity $(P)$ can be measured. The electron capacity (ET capacity, E) is obtained at optimum uncoupler concentrations, such as CCCP. On the other hand, the measurement of mtMP is performed using a lipophilic cation, which accumulates in the negatively charged mitochondrial matrix $[19,20]$.

This is the first report on the elucidation of mitochondrial functionality in ALCL using high-resolution respirometry.

\section{Materials and Methods}

\subsection{Chemicals}

All chemicals were purchased from Sigma-Aldrich (Sigma-Aldrich, Burlington, MA, USA) unless otherwise stated.

\subsection{Cell Culture}

Both lymphoblastoid cell lines (LCLs) were purchased from Autism Genetic Resource Exchange (AGRE; Los Angeles, CA, USA). The cells are derived from male siblings in which one sibling has been diagnosed with ASD (LCL derived from an autistic child, ALCL; Cell ID: 065604, aged 11) and the healthy control was from an apparently healthy sibling with no observation of behavioral and neurological disorders (LCL derived from a non-autistic sibling, NALCL; Cell ID: 065603, aged 12). The parents of the siblings were 
healthy and the ethnicity of the family was classified as non-Hispanic or Latino. The DNA of the ASD patient was tested for mutation of the Fragile-X syndrome gene, the FMR1 gene, and no known mutation was found.

The cell lines were cultured in complete culture media that consist of Rosewell Park Memorial Institute (RPMI) 1640 media supplemented with a volume fraction of $0.15 \%$ fetal bovine serum, $2 \mathrm{mM}$ L-glutamine, $100 \mathrm{U} \cdot \mathrm{mL}^{-1}$ penicillin, and $100 \mathrm{U} \cdot \mathrm{mL}^{-1}$ streptomycin (Gibco, Carlsbad, CA, USA) at $37^{\circ} \mathrm{C}$ in an incubator with $5 \% \mathrm{CO}_{2}$. The LCLs used in this study were within passages 8 to 10 .

LCLs were centrifuged at $130 \times g$ and $5 \times 10^{6}$ cells were resuspended in $300 \mu \mathrm{L}$ respiration medium, MiR05 (0.5 mM EGTA, $3 \mathrm{mM} \mathrm{MgCl} 2,60 \mathrm{mM}$ lactobionic acid, $20 \mathrm{mM}$ taurine, $10 \mathrm{mM} \mathrm{KH}_{2} \mathrm{PO}_{4}, 20 \mathrm{mM}$ HEPES, $110 \mathrm{mM}$ D-sucrose, 1.0\% (w/v) bovine serum albumin) and $\mathrm{pH}$ was adjusted to 7.1 with $\mathrm{KOH}$ at $30^{\circ} \mathrm{C}$.

\subsection{High-Resolution Respirometry}

All experiments were performed using a modular instrument for high-resolution respirometry (HRR) and fluorometry, the Oxygraph-2k (O2k; Oroboros Instruments, Innsbruck, Austria). The temperature of the experimental chamber was kept at $37^{\circ} \mathrm{C}$ with constant stirring at $750 \mathrm{rpm}$ to ensure a homogeneous oxygen distribution in the chamber without cell disruption. Air calibration of the oxygen sensors was performed daily. DatLab 7 software (Oroboros Instruments) was used for real-time data acquisition and analysis. The oxygen concentration was kept at and below air saturation (normoxic conditions). The O2k chambers were filled with $2.0 \mathrm{~mL}$ MiR05 equilibrated at $37^{\circ} \mathrm{C}$. Titrations were performed manually by injection into O2k chambers using precalibrated Hamilton microsyringes. Substrate concentrations and respiratory states are listed in Tables 1 and 2, respectively. Oxygen consumption rates were normalized to cell number and expressed as $\mathrm{O}_{2}$ flow per cell $\left[\mathrm{amol} \cdot \mathrm{s}^{-1} \cdot \mathrm{cell}^{-1}\right]$.

Table 1. Substrates, uncoupler, and inhibitors used in respirometry protocol to induce different respiratory states [20,21].

\begin{tabular}{|c|c|c|}
\hline Substrates & Function & Concentration \\
\hline Digitonin (Dig) & Plasma membrane permeabilization & $\begin{array}{l}7.5 \mu \mathrm{g} \cdot \mathrm{mL}^{-1}(\mathrm{NALCL}) \\
27.5 \mu \mathrm{g} \cdot \mathrm{mL}^{-1}(\mathrm{ALCL})\end{array}$ \\
\hline Pyruvate $(\mathrm{P})$ & & $5 \mathrm{mM}$ \\
\hline Glutamate $(\mathrm{G})$ & NADH-generating substrate (Substrates for CI) & $10 \mathrm{mM}$ \\
\hline Malate (M) & & $2 \mathrm{mM}$ \\
\hline Succinate (S) & CII substrate & $10 \mathrm{mM}$ \\
\hline Ascorbate (As) & Maintains TMPD in a reduced state & $2 \mathrm{mM}$ \\
\hline $\begin{array}{c}\mathrm{N}, \mathrm{N}, \mathrm{N}^{\prime}, \mathrm{N}^{\prime} \text {-tetramethyl-p- } \\
\text { phenylenediamine dihydrochloride } \\
\text { (TMPD) }\end{array}$ & $\begin{array}{l}\text { Substrate for reducing cytochrome } c \\
\text { (Substrate for CIV) }\end{array}$ & $0.5 \mathrm{mM}$ \\
\hline Cytochrome $c(c)$ & Mitochondrial outer membrane permeability test & $10 \mu \mathrm{M}$ \\
\hline $\mathrm{ADP}(\mathrm{D})$ & Substrate of ANT, $\mathrm{F}_{1} \mathrm{~F}_{0}$-ATPase (Substrate for CV) & $2.5 \mathrm{mM}$ \\
\hline $\begin{array}{l}\text { Carbonyl cyanide m-chlorophenyl } \\
\text { hydrazone, CCCP (U) }\end{array}$ & Uncoupler, protonophore & $0.5 \mu \mathrm{M}$ steps \\
\hline Rotenone (Rot) & CI inhibitor & $0.5 \mu \mathrm{M}$ \\
\hline Malonate (Mna) & CII inhibitor & $5 \mathrm{mM}$ \\
\hline Antimycin A (Ama) & CIII inhibitor & $2.5 \mu \mathrm{M}$ \\
\hline Sodium azide (Azd) & CIV inhibitor & $100 \mathrm{mM}$ \\
\hline Oligomycin (Omy) & ATP synthase inhibitor & $2.5 \mu \mathrm{M}$ \\
\hline Safranin (Saf) & $\begin{array}{l}\text { Fluorophore, dye for measuring mitochondrial } \\
\text { membrane potential }\end{array}$ & $2 \mu \mathrm{M}$ \\
\hline
\end{tabular}


Table 2. Definitions of respiratory states [22-24].

\begin{tabular}{|c|c|}
\hline States and Ratios & Definition and Rate \\
\hline N-pathway (CI-linked pathway) & $\begin{array}{l}\text { Respiration induced by the addition of NADH-generating substrates. Electrons are } \\
\text { transferred from CI to CIII and then to CIV. }\end{array}$ \\
\hline S-pathway (CII-linked pathway) & $\begin{array}{l}\text { Respiration induced by the addition of succinate and Rot. CI is inhibited by Rot } \\
\text { while electrons can only be generated by CII, transferred to CIII and then to CIV. }\end{array}$ \\
\hline NS-pathway (CI- and CII-linked pathways) & $\begin{array}{l}\text { Respiration induced by the addition of NADH-generating substrates and succinate } \\
\text { without Rot. Combination of both pathways (usual pathway) whereby electrons } \\
\text { move from both CI and CII, to CIII and then to CIV. }\end{array}$ \\
\hline ROUTINE, $R$ & $\begin{array}{l}\text { ROUTINE respiration controlled by intrinsic energy demand. This represents } \\
\text { energy demand under steady-state conditions. }\end{array}$ \\
\hline LEAK, $L$ & $\begin{array}{l}\text { LEAK respiration caused by proton leak, proton slip, cation cycling, and electron } \\
\text { leak. } L \text { is measured in the presence of reducing substrate(s) but absence of ADP or } \\
\text { after enzymatic inhibition of the phosphorylation system by Omy. }\end{array}$ \\
\hline OXPHOS, $P$ & $\begin{array}{l}\text { Respiration in the ADP-stimulated state of oxidative phosphorylation; } \\
\text { OXPHOS capacity. }\end{array}$ \\
\hline ET, E & $\begin{array}{l}\text { Oxygen consumption in the non-coupled state at optimum uncoupler } \\
\text { concentration, ET capacity. }\end{array}$ \\
\hline ROX, Rox & Residual oxygen consumption, measured after inhibition of the ETS. \\
\hline$(E-P) / E$ & $\begin{array}{l}\text { Relative } E-P \text { excess capacity, defines the limitation of OXPHOS capacity exerted } \\
\text { by the phosphorylation system. }\end{array}$ \\
\hline$(P-L) / P$ & $\begin{array}{c}\text { OXPHOS coupling efficiency, combining the effects of coupling and limitation by } \\
\text { the phosphorylation system. }\end{array}$ \\
\hline
\end{tabular}

\subsection{Cytochrome c Oxidase (CIV) Activity Assay}

Cells in MiR05 were titrated into each chamber, followed by titration of digitonin $\left(7.5 \mu \mathrm{g} \cdot \mathrm{mL}^{-1}\right.$ for NALCL, $27.5 \mu \mathrm{g} \cdot \mathrm{mL}^{-1}$ for ALCL). CIII was inhibited by the addition of antimycin A $(2.5 \mu \mathrm{M})$. Stepwise titration of the protonophore CCCP $(0.5 \mu \mathrm{M}$ steps $)$ leads to proton leakage across the mitochondrial inner membrane. Ascorbate $(2 \mathrm{mM})$ was added before the addition of TMPD $(0.5 \mathrm{mM})$ to avoid uncontrolled autoxidation and to maintain TMPD in a reduced state. The artificial substrate TMPD reduced cytochrome c. The activity of CIV was later inhibited by the addition of sodium azide $(100 \mathrm{mM})$. Chemical background due to the autoxidation of ascorbate, TMPD, and cytochrome $c$ was assessed after the inhibition of CIV by sodium azide. Chemical background correction was performed using DatLab 7. The CIV activity was expressed as a function of oxygen concentration. The protocols for measuring CIV activities in NALCL and ALCL were shown in Figure 1a and Figure 1b respectively.

\subsection{Respiration}

The addition of the NADH-linked substrates pyruvate $(\mathrm{P} ; 5 \mathrm{mM})$ and malate $(\mathrm{M} ; 2 \mathrm{mM})$ induced non-phosphorylating LEAK respiration, $\mathrm{N}(\mathrm{GM})_{L}$. Subsequently, N-OXPHOS capacity, $\mathrm{N}(\mathrm{GM})_{P}$, was measured after the addition of a saturating concentration of ADP $(2.5 \mathrm{mM})$. Cytochrome $c(10 \mu \mathrm{M})$ was added to test the integrity of the mitochondrial outer membrane damage. Glutamate $(10 \mathrm{mM})$ was added to stimulate multiple NADH hydrogenases, $\mathrm{N}(\mathrm{PGM})_{P}$. The addition of succinate $(\mathrm{S} ; 10 \mathrm{mM})$ stimulated the OXPHOS capacity of the combined $\mathrm{N}$ - and S-pathways $\left(\mathrm{NS}_{P}\right)$. Stepwise titration of the CCCP $(0.5 \mu \mathrm{M}$ steps) was used to measure the capacity of the ETS $\left(\mathrm{NS}_{E}\right)$. Then, $\mathrm{CI}$ was inhibited by rotenone $(0.5 \mu \mathrm{M})$ to measure S-ET capacity $\left(S_{E}\right)$. The inhibition of CIII by antimycin A $(2.5 \mu \mathrm{M})$ provided a measure of Rox. For further methodological details see [21]. The protocols for measuring respiration in NALCL and ALCL were shown in Figure 2a and Figure $2 b$ respectively. 


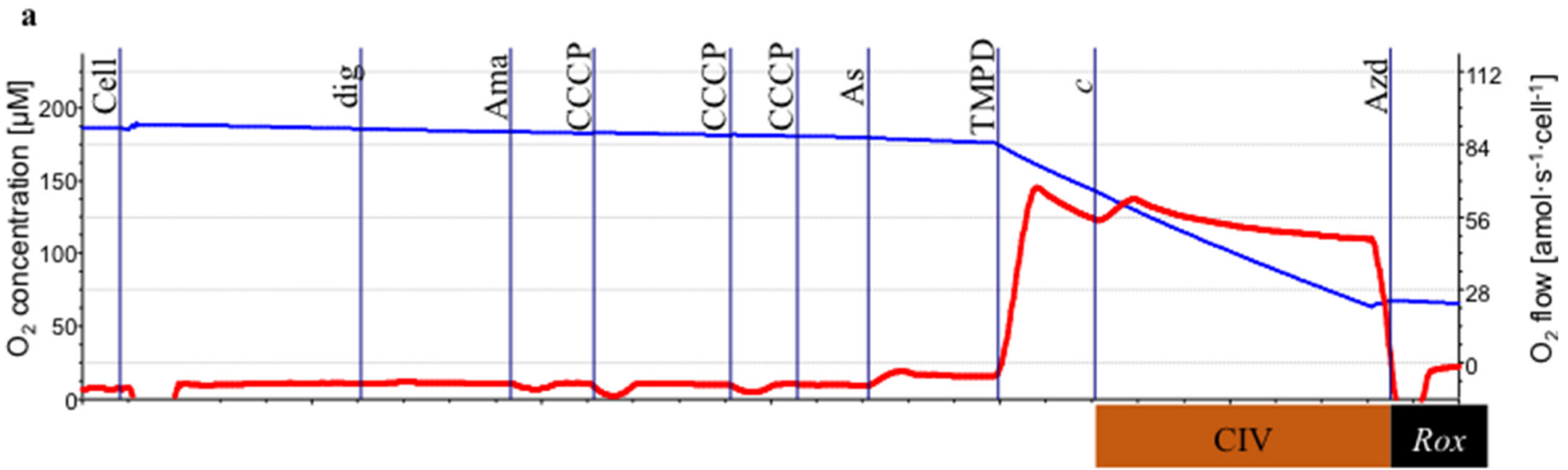

b

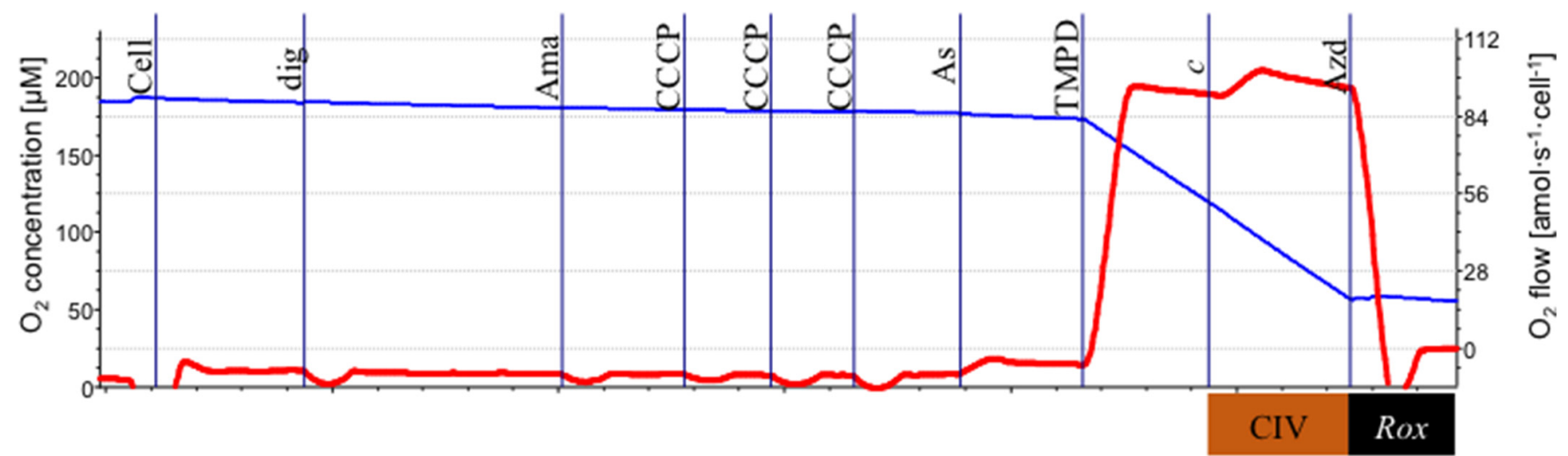

c

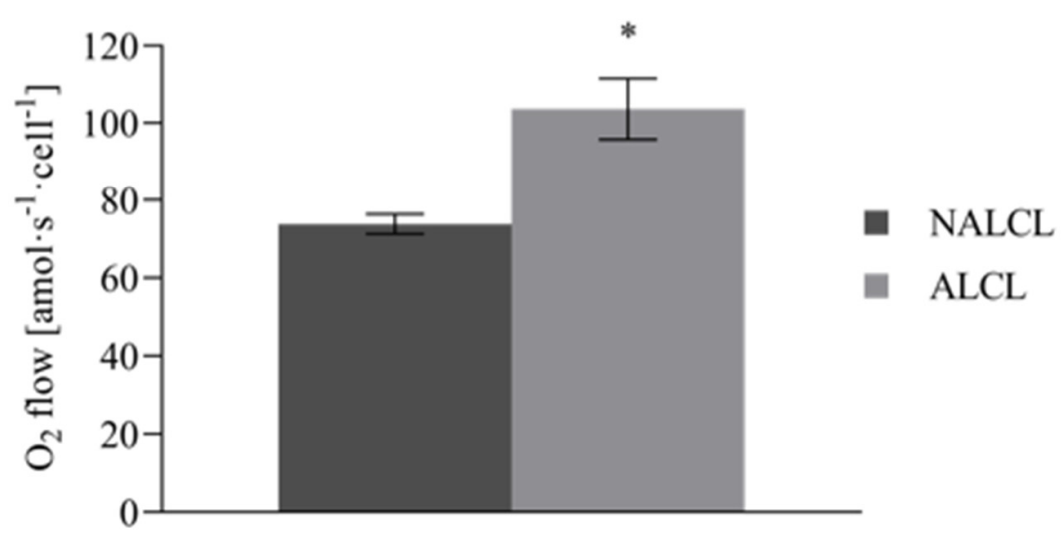

Figure 1. Cytochrome $c$ oxidase (CIV) activities of NALCL and ALCL. $(\mathbf{a}, \mathbf{b})$ are the protocols for measuring CIV activities in NALCL and ALCL, respectively. Titrations: Cell, dig (digitonin, cell permeabilization), Ama (antimycin A, CIII inhibition), CCCP (oxidative phosphorylation uncoupling), As (ascorbate, maintaining TMPD in a reduced state), TMPD (reducing cytochrome $c$ ), $c$ (cytochrome $c$ integrity of outer mt-membrane), and Azd (azide, CIV inhibition). Blue plots indicate $\mathrm{O}_{2}$ concentration and red plots are the $\mathrm{O}_{2}$ consumption expressed per cell. (c) The total $\mathrm{O}_{2}$ consumption rate was baselinecorrected for autoxidation after inhibition of CIV. Results are expressed as means \pm S.D. * denotes $p<0.05$ compared to NALCL as determined by $t$-test. 
a

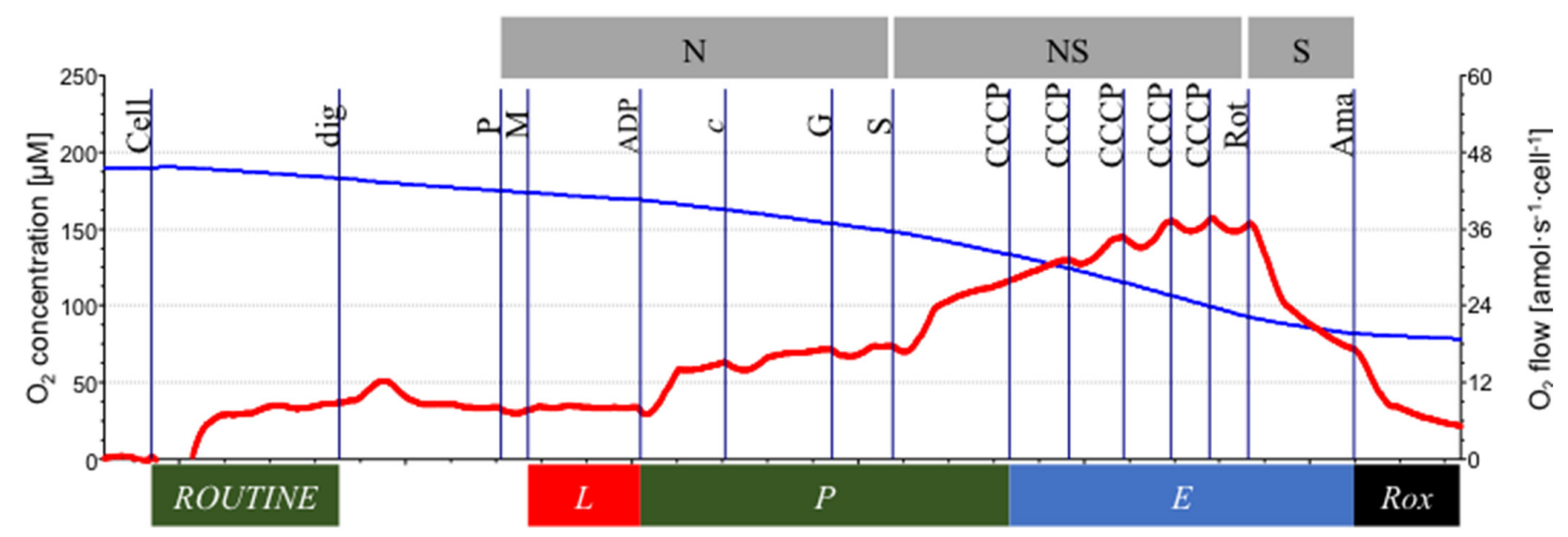

b

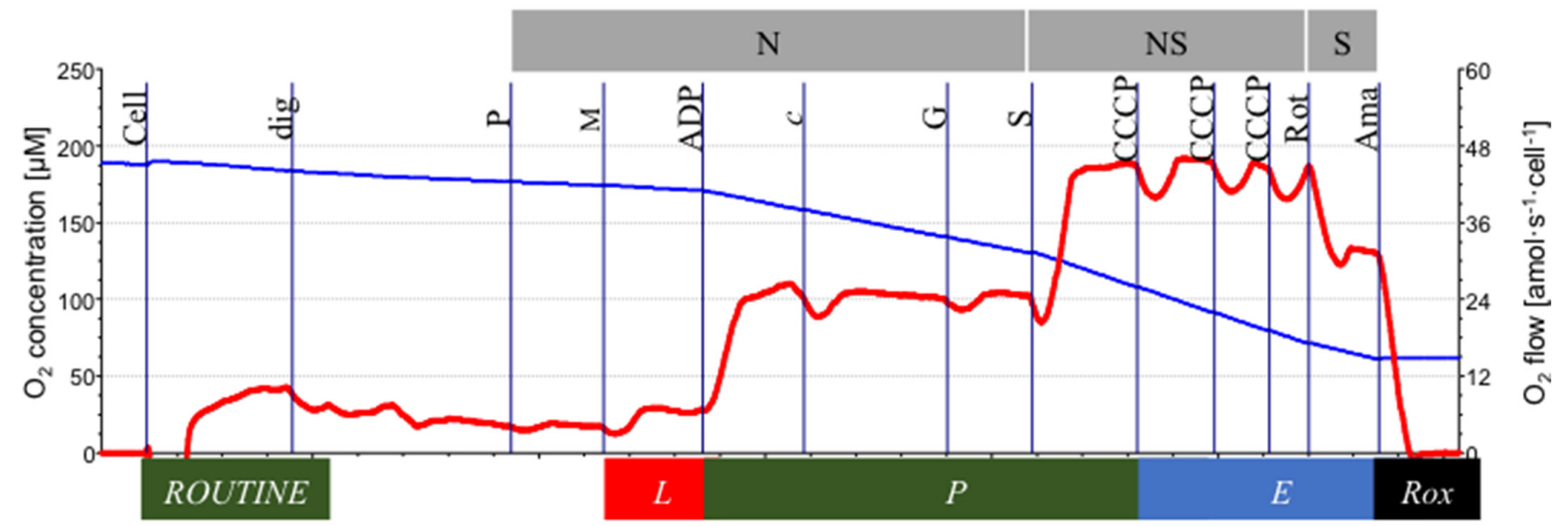

c

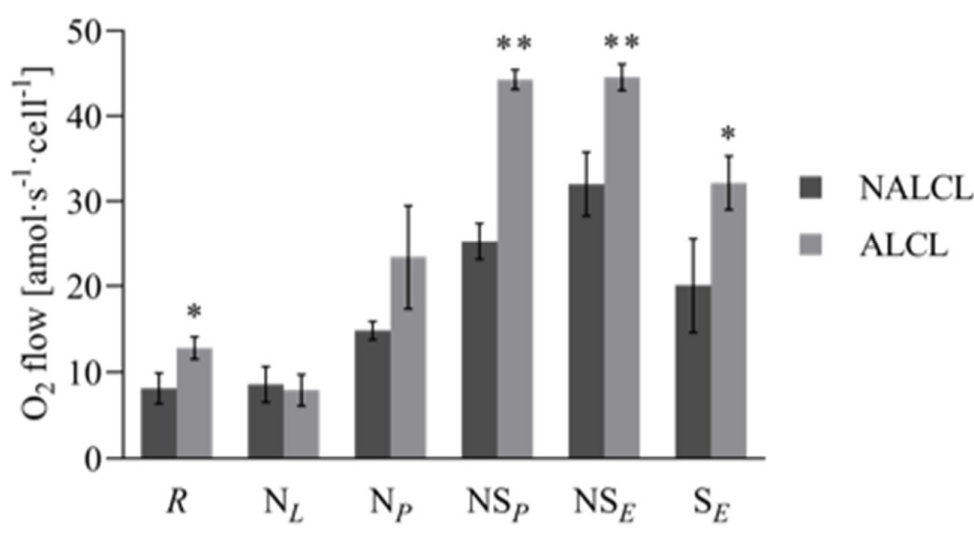

Figure 2. Mitochondrial respiration of NALCL and ALCL. $(\mathbf{a}, \mathbf{b})$ are the protocols for measuring respiration in NALCL and ALCL, respectively. Titrations: Cell, dig (digitonin, cell permeabilization), P and M (pyruvate and malate, nonphosphorylating N-LEAK respiration, $\left.\mathrm{N}(\mathrm{GM})_{L(\mathrm{n})}\right)$, ADP $\left(\mathrm{N}-\mathrm{OXPHOS}\right.$ capacity, $\left.\mathrm{N}(\mathrm{GM})_{P}\right), c($ cytochrome $c$ integrity of outer mt-membrane), G (glutamate, N-OXPHOS capacity, N(PGM) $)$ ), S (succinate, NS-OXPHOS, NS $)_{P}$ ), CCCP (NS-ET capacity, $\mathrm{NS}_{E}$ ), Rot (rotenone, $\mathrm{CI}$ inhibition, S-ET capacity, $\mathrm{S}_{E}$ ), and Ama (antimycin A, CIII inhibition, Rox). Oxygen consumption was corrected for Rox. Blue plots indicate $\mathrm{O}_{2}$ concentration and red plots are the $\mathrm{O}_{2}$ consumption expressed per cell. (c) The Rox-corrected respiration: ROUTINE respiration, $R$, was measured in non-permeabilized cells in MiR05. After plasma membrane permeabilization, five respiratory states were sequentially established to measure NADH-linked LEAK respiration with pyruvate and malate, $\mathrm{N}_{L}$, OXPHOS capacity, $\mathrm{N}_{P}$, NS-pathway OXPHOS capacity, NS $S_{P}$, and NSand S-pathway ET capacity, $\mathrm{NS}_{E}$ and $\mathrm{S}_{E}$, where $S$ indicates the succinate pathway. Results are expressed as means \pm S.D. * denotes $p<0.05$ while ${ }^{* *}$ denotes $p<0.01$ compared to NALCL as determined by $t$-test. 


\subsection{Mitochondrial Membrane Potential}

The Fluorescence-Sensor Blue of the O2k-Fluorescence LED2-Module was used with filter sets for safranin. Two sensors were inserted through the front windows of the O2kchambers. Following air calibration, the chamber illumination was switched off. HRR provides simultaneous measurement of respiration and the safranin signal in each chamber [20]. The polarization voltage regulating light intensity was set at $500 \mathrm{mV}$ at gain 1000 . Safranin is a fluorophore with an excitation wavelength of $495 \mathrm{~nm}$ and an emission wavelength of $587 \mathrm{~nm}$, and it is a lipophilic cation that accumulates in mitochondria depending on the inside negative potential in energized mitochondria $[19,20]$. Upon accumulation in the matrix, safranin undergoes a change in absorption and self-quenching of fluorescence $[25,26]$. Fluorescence intensity is linearly related to mtMP [27]. For calibration, a $200 \mu \mathrm{M}$ stock solution of safranin was titrated in five steps to obtain final concentrations of $0.25,0.5,1.0,1.5$, and $2.0 \mu \mathrm{M}$, obtaining a linear increase of the fluorescence signal as a function of safranin concentration in the chamber. Cells were then added to the chambers. In the absence of respiratory inhibitors, the mtMP builds up on the basis of endogenous substrates, and a corresponding amount of the dye accumulates in the mitochondrial matrix (i.e., the initial decline of the fluorescence signal). In addition, a fraction of safranin binds non-specifically to cell membranes. Therefore, the free safranin concentration is lower than the total safranin concentration added to the chamber [20]. As safranin inhibits N-pathway OXPHOS capacity $[19,20]$, only S-linked respiration was measured. $S_{L(n)}$ was induced by adding succinate $(10 \mathrm{mM})$ in the presence of rotenone $(0.5 \mu \mathrm{M})$ that inhibited CI. The titration of rotenone prevents the accumulation of oxaloacetate, which is a potent inhibitor of CII. Subsequently, $S_{P}$ was measured after the addition of a saturating concentration of ADP $(2.5 \mathrm{mM}) . \mathrm{S}_{L(\mathrm{Omy})}$ was induced by adding oligomycin $(2.5 \mu \mathrm{M})$ that inhibited $\mathrm{F}_{1} \mathrm{~F}_{0}$-ATPase (ATP synthase). Stepwise titration of the CCCP $\left(0.5 \mu \mathrm{M}\right.$ steps) was used to measure $S_{E}$. The inhibition of CIII by antimycin A $(2.5 \mu \mathrm{M})$ provided a measure of Rox. Figure 3c,d were the protocols for measuring mitochondrial membrane potential (mtMP) using safranin concentration in NALCL and ALCL, respectively. The Rox-corrected respiration was shown in Figure $3 e$.

\subsection{Data Analysis}

Oroboros DatLab 7 was used to calculate respiration corrected for instrumental background oxygen flux and graphical presentation of experimental data. Three variants of cell lines for ALCL and NALCL were used and three independent experiments were performed for each protocol type. Data are expressed as means \pm standard deviation. Statistical analyses using SPSS statistical software version 16 and $t$-test were applied to determine the significant differences among the groups, where $p<0.05$ was considered significant. 


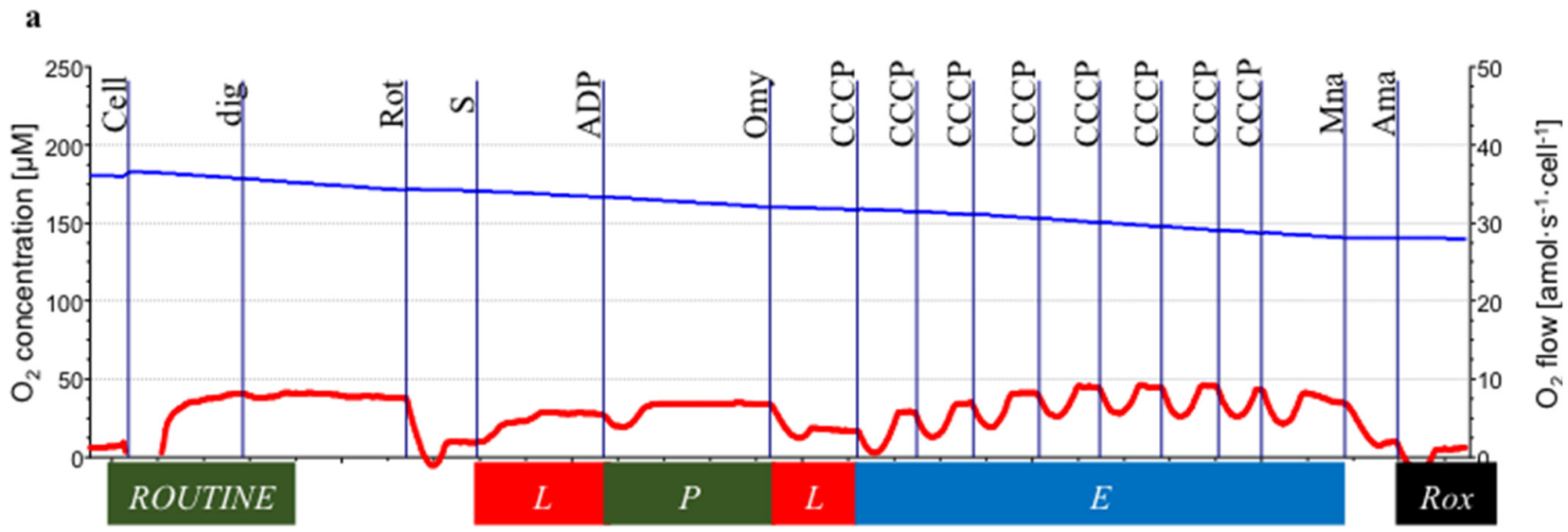

b

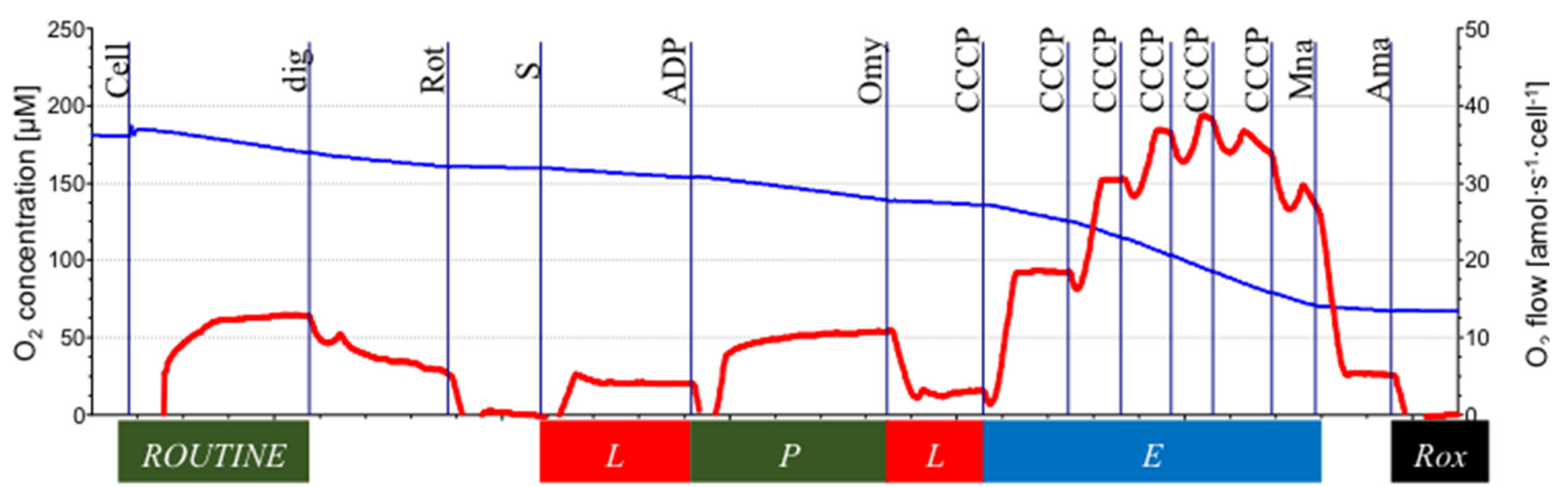

c

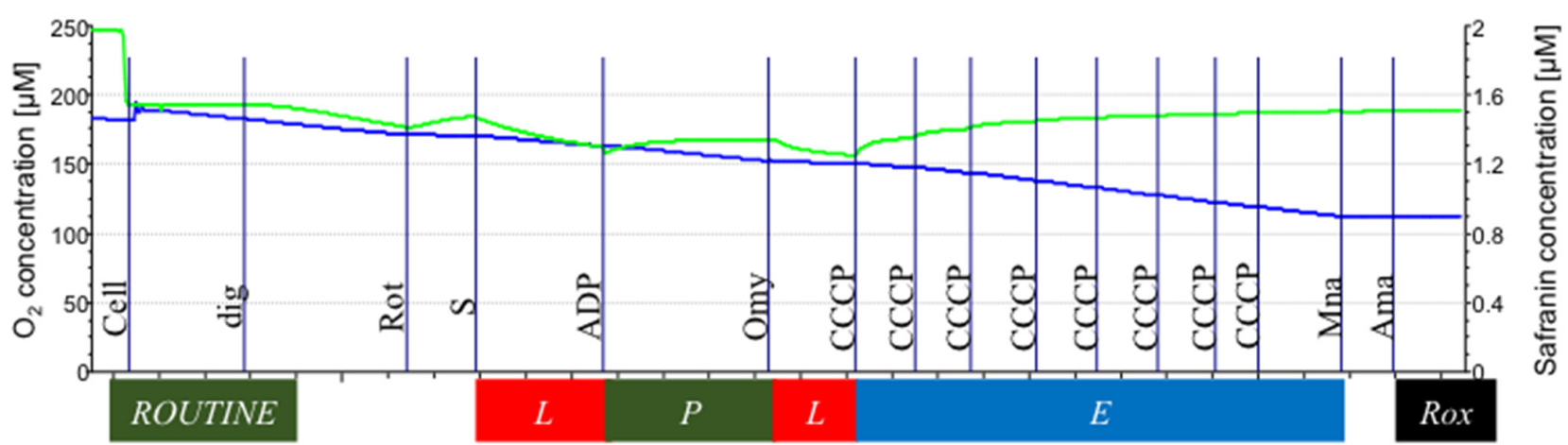

d

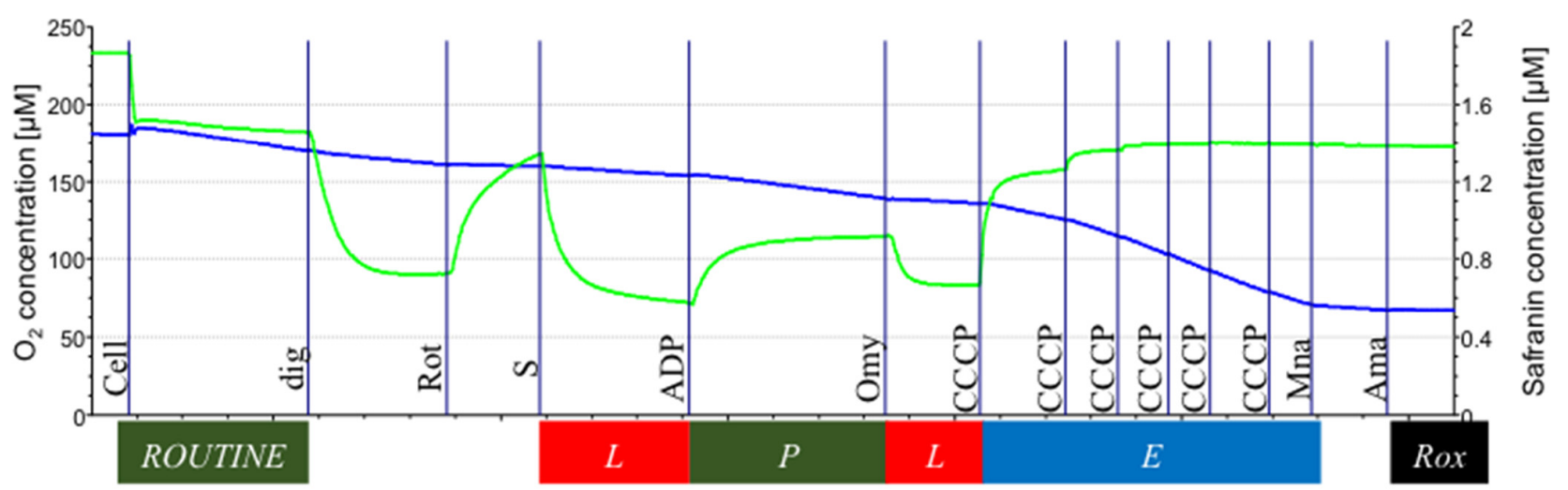

Figure 3. Cont. 


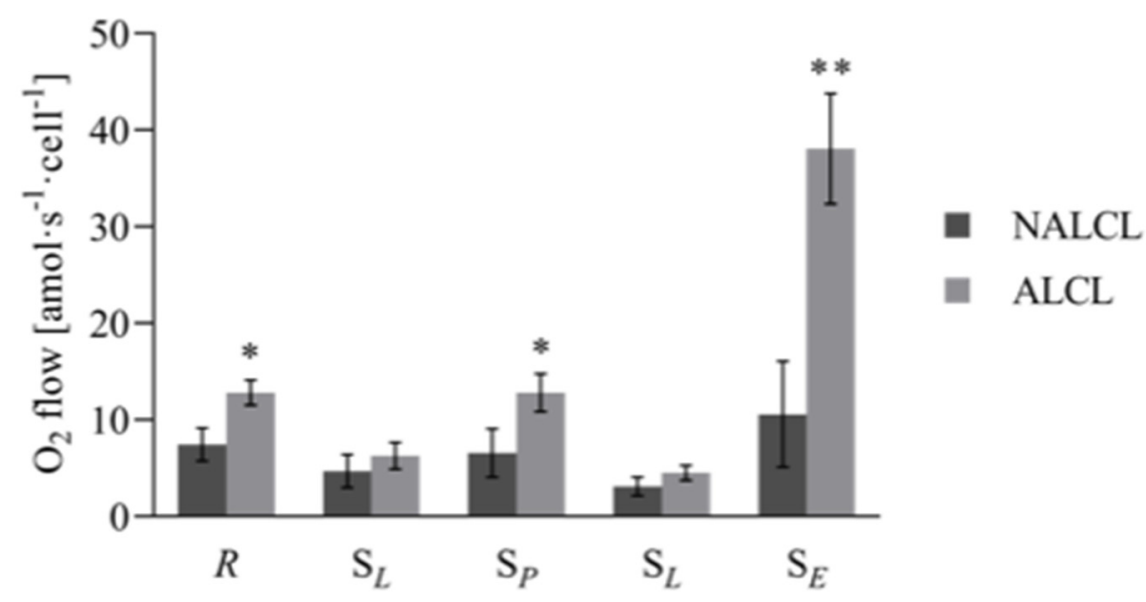

f

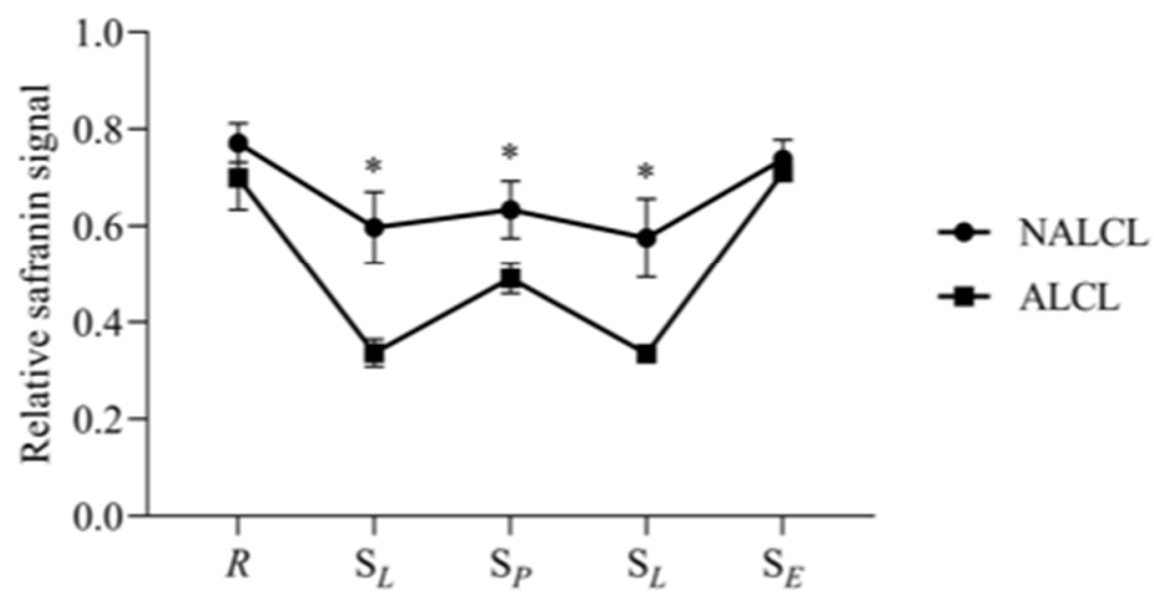

Figure 3. Succinate-linked respiration of NALCL and ALCL measured simultaneously with mitochondrial membrane potential in the presence of safranin. $(\mathbf{a}, \mathbf{b})$ are the protocols for measuring respiration in NALCL and ALCL, respectively, while $(\mathbf{c}, \mathbf{d})$ are the protocols for measuring mitochondrial membrane potential, mtMP using safranin concentration in NALCL and ALCL, respectively. Before the cells were added, safranin was calibrated up to $2 \mu \mathrm{M}$. The initial drop to $1.6 \mu \mathrm{M}$ safranin is mainly due to unspecific binding upon the addition of cells. Low safranin concentrations indicate high mtMP. Titrations: Cell, dig (digitonin, cell permeabilization), Rot (rotenone, CI inhibition), S (succinate, S-LEAK respiration, $\mathrm{S}_{L(\mathrm{n})}$ ), ADP (S-OXPHOS capacity, $\mathrm{S}_{P}$ ), Omy (oligomycin, S-LEAK, $\mathrm{S}_{L(\text { Omy })}$ ), CCCP (S-ET capacity, $\mathrm{S}_{E}$ ), Mna (malonate, CII inhibition), and Ama (antimycin A, CIII inhibition, Rox). Oxygen consumption was corrected for Rox. Blue plots indicate $\mathrm{O}_{2}$ concentration, red plots are the $\mathrm{O}_{2}$ consumption expressed per cell, and neon plots indicate safranin concentrations. (e) The Rox-corrected respiration and (f) the relative safranin signal: ROUTINE state, $R$, and in four respiratory states in permeabilized cells: S-linked LEAK respiration in the absence of adenylates, $S_{L(n)}$, S-linked OXPHOS capacity, $S_{P}$, S-linked LEAK respiration after inhibition of ATP synthase by oligomycin, $S_{L(O m y)}$, and S-linked ET capacity, $S_{E}$. Results are expressed as mean \pm S.D. ${ }^{*}$ denotes $p<0.05$ while ${ }^{* *}$ denotes $p<0.01$ compared to NALCL as determined by Student's $t$-test.

\section{Results}

\subsection{Complex IV Activity}

The CIV activity of NALCL was $55.9 \pm 10.4 \mathrm{amol} \cdot \mathrm{s}^{-1} \cdot \mathrm{cell}^{-1}$, while the activity in ALCL was 1.73-fold higher $\left(96.7 \pm 15.9 \mathrm{amol} \cdot \mathrm{s}^{-1} \cdot \mathrm{cell}^{-1}\right)$ (Figure 1c). 


\subsection{Mitochondrial Respiration}

In this study, the first respiration rate measured in both cell lines is the ROUTINE respiration which represents energy demand under steady-state conditions. ROUTINE respiration, in ALCL, was significantly higher $\left(12.8 \pm 1.3 \mathrm{amol} \cdot \mathrm{s}^{-1} \cdot \mathrm{cell}^{-1}\right)$ compared to NALCL $\left(8.1 \pm 1.8 \mathrm{amol} \cdot \mathrm{s}^{-1}\right.$. cell $\left.{ }^{-1}\right)$. A digitonin concentration, Dig, of $7.5 \mu \mathrm{g} \cdot \mathrm{mL}^{-1}$ was optimal for NALCL and $27.5 \mu \mathrm{g} \cdot \mathrm{mL}^{-1}$ for ALCL for complete permeabilization of the plasma membrane without affecting the mitochondrial membranes.

N-LEAK respiration with pyruvate and malate, $\mathrm{N}_{L}$, was $8.6 \pm 2.1$ and $7.9 \pm 1.8 \mathrm{amol} \cdot \mathrm{s}^{-1} \cdot \mathrm{cell}^{-1}$ in NALCL and ALCL, respectively (Figure 2c). After the addition of ADP, the N-OXPHOS capacity, $\mathrm{N}_{P}$, in NALCL and ALCL was $14.8 \pm 1.1$ and $23.4 \pm 6.1 \mathrm{amol} \cdot \mathrm{s}^{-1} \cdot \mathrm{cell}^{-1}$, respectively (Figure $2 \mathrm{c}$ ). This yields OXPHOS coupling efficiencies, $(P-L) / P$, of 0.42 and 0.66 for NALCL and ALCL, respectively.

Further stimulation of respiration with succinate activates convergent entry through the S-linked pathway via CII in addition to the N-pathway through CI, which results in NSlinked OXPHOS capacity $\left(\mathrm{NS}_{P}\right)$. The $\mathrm{NS}_{P}$ of NALCL increased 1.7-fold to $25.3 \pm 2.1 \mathrm{amol} \cdot \mathrm{s}^{-1} \cdot$ cell $^{-1}$, indicating a strongly additive effect. The $\mathrm{NS}_{P}$ of ALCL was significantly higher than in NALCL $\left(44.3 \pm 1.2 \mathrm{amol} \cdot \mathrm{s}^{-1} \cdot \mathrm{cell}^{-1}\right)$, which is a 1.9 -fold increase with respect to $\mathrm{N}_{\mathrm{P}}$.

The non-coupled NS-ET capacity, $\mathrm{NS}_{E}$, of ALCL, was $44.6 \pm 1.5 \mathrm{amol} \cdot \mathrm{s}^{-1} \cdot \mathrm{cell}^{-1}$, which was significantly higher than in NALCL $\left(32.0 \pm 3.8 \mathrm{amol} \cdot \mathrm{s}^{-1} \cdot \mathrm{cell}^{-1}\right)$.

After inhibition of the N-pathway by rotenone, S-ET capacity $\left(\mathrm{S}_{E}\right)$ was $20.1 \pm 5.5$ and $32.2 \pm 3.2 \mathrm{amol} \cdot \mathrm{s}^{-1} \cdot \mathrm{cell}^{-1}$ in NALCL and ALCL, respectively. The NS-linked P/E ratio $\left(\mathrm{NS}_{P / E}\right)$ in NALCL (0.21) was higher than in ALCL (0.01). The P/E coupling control ratio describes the function of the phosphorylation system as a crucial controller limiting OXPHOS capacity. A ratio of 1.0 indicates no limitation by the phosphorylation system.

\subsection{Mitochondrial Membrane Potential}

MtMP was measured in the S-pathway simultaneously with respiration in the same chamber. Rotenone and succinate were added simultaneously to establish the LEAK state in the absence of exogenous ADP and ATP (no adenylates), $S_{L(n)}$. $S_{L}$ was similar in NALCL and ALCL ( $4.7 \pm 1.7$ and $6.3 \pm 1.4 \mathrm{amol} \cdot \mathrm{s}^{-1} \cdot$ cell $^{-1}$, respectively). OXPHOS capacity, $\mathrm{S}_{P}$ was significantly lower in NALCL than ALCL $\left(6.6 \pm 2.5\right.$ and $12.8 \pm 2.0 \mathrm{amol} \cdot \mathrm{s}^{-1} \cdot \mathrm{cell}^{-1}$, respectively). In both cell lines, the inhibition of ATPase by oligomycin inhibited LEAK respiration, $S_{L(\text { Omy })}$, was below the level of $S_{L(n)}$, indicating an overestimation of LEAK in the absence of inhibition of the phosphorylation system due to some recycling of endogenous ATP to ADP by ATPases (Figure $3 a, b$ ). OXPHOS coupling efficiencies were 0.29 and 0.51 in the absence of oligomycin, but 0.53 and 0.65 in the presence of oligomycin for NALCL and ALCL, respectively. The S-pathway ET capacity in the mtMP protocol was obtained by stepwise titration of CCCP up to reaching maximum respiration.

In the S-pathway with electron entry into the Q-junction through CII and only two coupling sites downstream, the P/E ratios increased to 0.67 and 0.60 in NALCL and ALCL, respectively, indicating the lower limit in the phosphorylation system. On the other hand, the LEAK/OXPHOS $\left(S_{L / P}\right)$ ratio depicts respiration triggered by membrane leakiness in comparison to OXPHOS capacity. The mitochondrial membrane leakiness appeared higher in NALCL with an $L / P$ ratio of 0.72 , while in ALCL, the $L / P$ ratio was 0.49 .

During ROUTINE respiration of intact cells, the safranin signals showed no significant difference between NALCL and ALCL (Figure 3f). After plasma membrane permeabilization, the mtMP increased in both cell lines as S-linked respiration was stimulated by the addition of succinate in the presence of Rot, as reflected by a decline of safranin fluorescence. The mtMP in ALCL showed a higher increase than in NALCL during LEAK $(p<0.01)$ and OXPHOS ( $p<0.05$; Figure 3f). There was no significant difference between mtMP in NALCL and ALCL during ET capacity measurement. 


\section{Discussion}

$\mathrm{mtD}$ is often linked with oxidative stress as damaged mitochondria not only produce more reactive oxygen species (ROS, including $\mathrm{H}_{2} \mathrm{O}_{2}$ ) and reactive nitrogen species through OXPHOS, but mitochondria are also becoming more vulnerable to oxidative stress [28]. In the present study, we investigated the mtD concerning CIV activity, mitochondrial respiration through N-pathway (CI-linked), S-pathway (CII-linked), and both pathways as combined NS-pathway (CI- and CII-linked), and mtMP as the key markers of mitochondrial function.

The first respiratory state measured in this study is ROUTINE respiration. ROUTINE respiration is the respiration controlled by intrinsic energy demand. It represents energy demand under steady-state conditions. During ROUTINE respiration, cell respiration relies on endogenous substrates in the cells only.

The higher ROUTINE respiration rate in ALCL as compared to in NALCL showed that the intrinsic energy demand under steady-state conditions in ALCL is higher as compared to in NALCL. This situation is considered to be a compensatory response to the increased intrinsic energy demand in ALCL. Ideally, bioenergetic efficiency is achieved when there is a balance between energy supply and energy demand [29]. In response to changes in energy demand, mitochondria respond by adjusting both their capacity and efficiency of ATP production [29]. This might be reflected by the higher OXPHOS capacity in ALCL as compared to in NALCL. In an intact cell with high energy demand, nutrient utilization and its availability have very significant control over respiration as compared to ATP turnover [29].

It has been proposed that the increased respiration rate leads to higher oxidative stress and alterations in mitochondrial energy metabolism [30]. The higher OXPHOS capacity in ALCL might be linked to the over replication and a higher mtDNA copy number in ASD than in controls [31]. These conditions were observed in cells in response to oxidative stress [31]. mtDNA encodes some of the proteins of the complexes of the electron transfer system (ETS). Thus, an increase in mtDNA copy number possibly leads to an increased expression of ETS complexes, resulting in a higher respiratory ET capacity. This, however, needs further clarification via real-time PCR to investigate the level of expression of ETS genes encoded in the mtDNA.

$\mathrm{mtD}$ from mtDNA mutations could lead to ETS instability, electron leakage, and increased ROS production [32]. Higher OXPHOS- and ET capacities would result in increased production of $\mathrm{H}_{2} \mathrm{O}_{2}$ and other ROS-inducing oxidative stress. A high level of $\mathrm{H}_{2} \mathrm{O}_{2}$ production is frequently observed in ASD patients compared to controls [33]. Our results are in line with another study that reported a $40 \%-50 \%$ increase in maximal respiratory rates in lymphoblasts of ASD patients as compared to the non-autism relative [34]. However, clarification of this hypothesis needs to be done via sequencing of the mtDNA of both cell lines.

CIV is the terminal respiratory complex of the ETS, which converts $\mathrm{O}_{2}$ to $\mathrm{H}_{2} \mathrm{O}$. Diminished activity of ETS complexes has been reported as a prevalent mitochondrial abnormality associated with ASD [4]. For example, lowered activities of CI, CIII, and CIV were found in ASD studies using muscle cells [35] and in the brain from post-mortem ASD patients [36,37]. However, CIV mitochondrial-dependent oxygen consumption was not different in peripheral blood lymphocytes from children with autism versus controls [33]. On the other hand, increased activity of CIV was detected in brain tissue [38,39]. Similarly, in the present study of human lymphoblastoid cell lines, the CIV activity was higher in ALCL compared to NALCL. This occurs to cope with the increase in the ET capacity of the NADH- and succinate pathways (CI and $\mathrm{CII}$ ), which results in higher production and the transfer of electrons toward CIV.

MtMP reflects the electrical potential difference across the mitochondrial inner membrane, where transmembrane $\mathrm{pH}$ difference is the driving force for ATP synthesis. Alterations in mtMP are strongly linked to the control of electron transfer and ATP synthesis [21,33,34] and are involved in apoptosis and necrosis [40]. In our study, the mtMP 
in ALCL was higher in S-OXPHOS respiration as compared to NALCL. This is in agreement with previous studies, which found that the mtMP in ASD is higher compared to controls $[28,41]$. Theoretically, the higher the mtMP would reflect the higher the energy capacity of the mitochondrial inner membrane and the higher the synthesis of ATP [42]. However, a high electric field is energetically expensive to maintain; thus, ion leakage would occur to compromise the mtMP [42]. This is reflected by a higher S-LEAK value in ALCL compared to NALCL. Mitochondrial ROS production by the mitochondrial transport system is increased at high membrane potential [42-44]. Fluctuations of the mtMP between different respiratory states are larger in ALCL than in NALCL. Such fluctuations may have deleterious effects on cell physiology [42]. Thus, high mtMP is potentially harmful to mitochondria and consequently to the cell [45].

On another note, classic $\mathrm{mtD}$ biomarkers are not always accurate. The elevation of pyruvate levels does not always reflect lower ET capacity. It could be due to impaired pyruvate metabolism and TCA cycle inhibition. Thus, an enzyme marker (e.g., CIV) can be used as a diagnostic tool for ASD and other mitochondrial diseases. It is also worth noting that ASD is a spectrum disorder in which different effects and causes may account for the link between $\mathrm{mtD}$ and various observed symptoms. Our findings suggest an involvement of mitochondria, particularly the complexes in the electron transport chain, such as CI, CII, and CIV, in the pathogenesis of ASD, specifically in idiopathic autism. This is tightly linked to the production of ROS by mitochondria as the possible underlying cause of ASD as $\mathrm{CI}$ is the biggest contributor of ROS production under pathological conditions, and both respiration rate and mtMP are proportional to $\mathrm{H}_{2} \mathrm{O}_{2}$ production [39,41,42].

These initial findings lead us to further directions that might include the exploration of mitochondrial elements in a bigger picture, such as measurement of mitochondrial density and determination of mitochondrial copy number. Other mitochondrial markers (e.g., measurement of the activity of citrate synthase) should be further explored for a wider understanding of the involvement of mitochondrial function in idiopathic autism. Altogether, these results indicate the correlation between mitochondrial function abnormalities and ASD. Novel and extended approaches are required to improve the diagnosis of mitochondrial function in ASD and find better intervention strategies.

\section{Conclusions}

Many mitochondrial diseases and $\mathrm{mtD}$ are characterized by lower activities of respiratory complexes and mitochondrial respiratory capacities, whereas we observed an opposite pattern in agreement with a few other studies on ASD. Thus, linking mtD to ASD should be revisited, and instead of mitochondrial 'dysfunction', mitochondrial 'dysregulation' represents a more accurate term in the context of ASD pathogenesis, especially in the case of idiopathic autism. Changes in mitochondrial respiratory capacities can be caused by a modification of mitochondrial quality or mitochondrial density. Both mechanisms may be implicated in the increased OXPHOS- and ET capacities, CIV activity, and mtMP in the autism lymphoblastoid cell lines, and may be linked to ROS production and oxidative stress, which needs further clarification and an interesting point to explore. These bioenergetic characteristics imply a disruption of nutrient homeostasis as a potential cause of the pathological symptoms prevalent in idiopathic autism.

\section{Limitations \& Future Direction}

This is a preliminary study that uses only one pair of LCL; ALCL versus NALCL, comparing the mitochondrial functions which are the CIV activity, respiration of intact and permeabilized cells, specifically in the ROUTINE, LEAK, OXPHOS and ETS respirations, and mtMP. This study provides an insight into the differences in mitochondrial function between cells derived from an autistic child compared to his apparently healthy sibling. The findings might provide an overview of a subset of ASD. The generalization on ASD as a whole, therefore, must be made cautiously. 
Future studies will, therefore, need to consider the gene mutation on both cell lines specifically in the mutations in the mtDNA.

Author Contributions: Conceptualization, H.H. and N.A.K.; methodology, H.H. and F.Z.; software, H.H. and F.Z.; validation, H.H., S.M. and N.A.K.; formal analysis, H.H.; investigation, H.H.; resources, N.A.K.; data curation, H.H.; writing—original draft preparation, H.H.; writing—review and editing, H.H., N.A.K. and S.M.; visualization, H.H.; supervision, N.A.K. and S.M.; project administration, N.A.K.; funding acquisition, N.A.K. All authors have read and agreed to the published version of the manuscript.

Funding: This work was supported by a grant from the Fundamental Research Grant Scheme (FRGS/1/2016/SKK06/UKM/03/1).

Institutional Review Board Statement: Not applicable.

Informed Consent Statement: Not applicable.

Data Availability Statement: The data presented in this study are available upon request from the corresponding author as the data is not available elsewhere.

Acknowledgments: Some chemicals used in this study were prepared by Siti Nor Rodhiah Rosaidee. We gratefully acknowledge the resources provided by Autism Genetic Resource Exchange (AGRE) and the participating AGRE families. The Autism Genetic Resource Exchange is a program of Autism Speaks.

Conflicts of Interest: The authors declare no conflict of interest.

\section{References}

1. Elsabbagh, M.; Divan, G.; Koh, Y.J.; Kim, Y.S.; Kauchali, S.; Marcin, C.; Montiel-Nava, C.; Patel, V.; Paula, C.S.; Wang, C.; et al. Global prevalence of autism and other pervasive developmental disorders. Autism Res. 2012, 5, 160-179. [CrossRef]

2. WHO. Autism Spectrum Disorders. Available online: https://www.who.int/news-room/fact-sheets/detail/autism-spectrumdisorders (accessed on 28 May 2019).

3. Lima Antão, J.Y.F.D.; Oliveira, A.S.B.; Almeida Barbosa, R.T.D.; Crocetta, T.B.; Guarnieri, R.; Arab, C.; Massetti, T.; Antunes, T.P.C.; Silva, A.P.D.; Bezerra, L.M.P.; et al. Instruments for augmentative and alternative communication for children with autism spectrum disorder: A systematic review. Clinics 2018, 73, e497.

4. Rossignol, D.A.; Frye, R.E. Mitochondrial dysfunction in autism spectrum disorders: A systematic review and meta-analysis. Mol. Psychiatry 2012, 17, 290-314. [CrossRef]

5. Manivasagam, T.; Arunadevi, S.; Essa, M.M.; SaravanaBabu, C.; Borah, A.; Thenmozhi, A.J.; Qoronfleh, M.W. Role of oxidative stress and antioxidants in autism. Adv. Neurobiol. 2020, 24, 193-206.

6. Pahrudin Arrozi, A.; Wan Ngah, W.Z.; Mohd Yusof, Y.A.; Ahmad Damanhuri, M.H.; Makpol, S. Antioxidant modulation in restoring mitochondrial function in neurodegeneration. Int. J. Neurosci. 2017, 127, 218-235. [CrossRef]

7. Islam, M.T. Oxidative stress and mitochondrial dysfunction-linked neurodegenerative disorders. Neurol. Res. 2017, 39, 73-82. [CrossRef]

8. Golpich, M.; Amini, E.; Mohamed, Z.; Azman Ali, R.; Mohamed Ibrahim, N.; Ahmadiani, A. Mitochondrial dysfunction and biogenesis in neurodegenerative diseases: Pathogenesis and treatment. CNS Neurosci. Ther. 2017, 23, 5-22. [CrossRef]

9. Scorza, F.A.; Menezes-Rodrigues, F.S.; Olszewer, E.; Errante, P.R.; Tavares, J.G.P.; Scorza, C.A.; Ferraz, H.B.; Finsterer, J.; CaricatiNeto, A. The mitochondrial calcium uniporter: A new therapeutic target for parkinson's disease-related cardiac dysfunctions? Clinics 2020, 75, e1299. [CrossRef]

10. Makpol, S.; Abdul Rahim, N.; Hui, C.K.; Ngah, W.Z. Inhibition of mitochondrial cytochrome c release and suppression of caspases by gamma-tocotrienol prevent apoptosis and delay aging in stress-induced premature senescence of skin fibroblasts. Oxid. Med. Cell. Longev. 2012, 2012, 785743. [CrossRef]

11. Palmieri, L.; Persico, A.M. Mitochondrial dysfunction in autism spectrum disorders: Cause or effect? Biochim. Biophys. Acta 2010, 1797, 1130-1137. [CrossRef]

12. Goldani, A.A.; Downs, S.R.; Widjaja, F.; Lawton, B.; Hendren, R.L. Biomarkers in autism. Front. Psychiatry 2014, 5, 100. [CrossRef]

13. Fernandez-Checa, J.C.; Kaplowitz, N.; Garcia-Ruiz, C.; Colell, A.; Miranda, M.; Mari, M.; Ardite, E.; Morales, A. Gsh transport in mitochondria: Defense against tnf-induced oxidative stress and alcohol-induced defect. Am. J. Physiol. 1997, 273, G7-G17. [CrossRef]

14. Gargus, J.J.; Imtiaz, F. Mitochondrial energy-deficient endophenotype in autism. Am. J. Biochem. Biotechnol. 2008, 4, 198-207. [CrossRef]

15. Obata, K. Synaptic inhibition and $\gamma$-aminobutyric acid in the mammalian central nervous system. Proc. Jpn. Acad. Ser. B Phys. Biol. Sci. 2013, 89, 139-156. [CrossRef] 
16. Anderson, M.P.; Hooker, B.S.; Herbert, M.R. Bridging from cells to cognition in autism pathophysiology: Biological pathways to defective brain function and plasticity. Am. J. Biochem. Biotechnol. 2008, 4, 167-176. [CrossRef]

17. Parikh, S.; Goldstein, A.; Koenig, M.K.; Scaglia, F.; Enns, G.M.; Saneto, R.; Anselm, I.; Cohen, B.H.; Falk, M.J.; Greene, C.; et al. Diagnosis and management of mitochondrial disease: A consensus statement from the mitochondrial medicine society. Genet. Med. 2015, 17, 689-701. [CrossRef]

18. Ghanizadeh, A.; Berk, M.; Farrashbandi, H.; Alavi Shoushtari, A.; Villagonzalo, K.A. Targeting the mitochondrial electron transport chain in autism, a systematic review and synthesis of a novel therapeutic approach. Mitochondrion 2013, 13, 515-519. [CrossRef]

19. Chowdhury, S.R.; Djordjevic, J.; Albensi, B.C.; Fernyhough, P. Simultaneous evaluation of substrate-dependent oxygen consumption rates and mitochondrial membrane potential by tmrm and safranin in cortical mitochondria. Biosci. Rep. 2015, 36, e00286. [CrossRef]

20. Krumschnabel, G.; Eigentler, A.; Fasching, M.; Gnaiger, E. Use of safranin for the assessment of mitochondrial membrane potential by high-resolution respirometry and fluorometry. Methods Enzymol. 2014, 542, 163-181.

21. Doerrier, C.; Garcia-Souza, L.F.; Krumschnabel, G.; Wohlfarter, Y.; Mészáros, A.T.; Gnaiger, E. High-resolution fluorespirometry and oxphos protocols for human cells, permeabilized fibers from small biopsies of muscle, and isolated mitochondria. Methods Mol. Biol. 2018, 1782, 31-70.

22. Gnaiger, E. Mitochondrial Pathways and Respiratory Control. An Introduction to Oxphos Analysis; Oroboros MiPNet Publications: Innsbruck, Austria, 2014; p. 88.

23. Gnaiger, E. Mitochondrial respiratory states and rates. MitoFit Prep. Arch. 2019, 1, 1-40.

24. Lemieux, H.; Blier, P.U.; Gnaiger, E. Remodeling pathway control of mitochondrial respiratory capacity by temperature in mouse heart: Electron flow through the q-junction in permeabilized fibers. Sci. Rep. 2017, 7, 2840. [CrossRef]

25. Perevoshchikova, I.V.; Sorochkina, A.I.; Zorov, D.B.; Antonenko, Y.N. Safranine o as a fluorescent probe for mitochondrial membrane potential studied on the single particle level and in suspension. Biochem. Biokhimiia 2009, 74, 663-671. [CrossRef]

26. Akerman, K.E.; Wikstrom, M.K. Safranine as a probe of the mitochondrial membrane potential. FEBS Lett. 1976, 68, 191-197. [CrossRef]

27. Figueira, T.R.; Melo, D.R.; Vercesi, A.E.; Castilho, R.F. Safranine as a fluorescent probe for the evaluation of mitochondrial membrane potential in isolated organelles and permeabilized cells. Methods Mol. Biol. 2012, 810, 103-117.

28. Chauhan, A.; Essa, M.M.; Muthaiyah, B.; Brown, W.T.; Chauhan, V. Mitochondrial abnormalities in lymphoblasts from autism. J. Neurochem. 2009, 109, 273. [CrossRef]

29. Liesa, M.; Shirihai, O.S. Mitochondrial dynamics in the regulation of nutrient utilization and energy expenditure. Cell Metab. 2013, 17, 491-506. [CrossRef]

30. Chauhan, A.; Gu, F.; Essa, M.M.; Wegiel, J.; Kaur, K.; Brown, W.T.; Chauhan, V. Brain region-specific deficit in mitochondrial electron transport chain complexes in children with autism. J. Neurochem. 2011, 117, 209-220. [CrossRef]

31. Liu, C.S.; Tsai, C.S.; Kuo, C.L.; Chen, H.W.; Lii, C.K.; Ma, Y.S.; Wei, Y.H. Oxidative stress-related alteration of the copy number of mitochondrial DNA in human leukocytes. Free Radic. Res. 2003, 37, 1307-1317. [CrossRef]

32. Soon, B.H.; Abdul Murad, N.A.; Then, S.M.; Abu Bakar, A.; Fadzil, F.; Thanabalan, J.; Mohd Haspani, M.S.; Toh, C.J.; Mohd Tamil, A.; Harun, R.; et al. Mitochondrial DNA mutations in grade ii and iii glioma cell lines are associated with significant mitochondrial dysfunction and higher oxidative stress. Front. Physiol. 2017, 8, 231. [CrossRef]

33. Giulivi, C.; Zhang, Y.F.; Omanska-Klusek, A.; Ross-Inta, C.; Wong, S.; Hertz-Picciotto, I.; Tassone, F.; Pessah, I.N. Mitochondrial dysfunction in autism. JAMA 2010, 304, 2389-2396. [CrossRef] [PubMed]

34. Benzecry, J.M.; Deth, R.; Holtzman, D. Abnormalities in respiratory properties of lymphoblasts in autistic spectrum disorders. Acta Paediatr. 2008, 97, 859-860.

35. Poling, J.S.; Frye, R.E.; Shoffner, J.; Zimmerman, A.W. Developmental regression and mitochondrial dysfunction in a child with autism. J. Child Neurol. 2006, 21, 170-172. [CrossRef] [PubMed]

36. Tang, G.; Gutierrez Rios, P.; Kuo, S.H.; Akman, H.O.; Rosoklija, G.; Tanji, K.; Dwork, A.; Schon, E.A.; Dimauro, S.; Goldman, J.; et al. Mitochondrial abnormalities in temporal lobe of autistic brain. Neurobiol. Dis. 2013, 54, 349-361. [CrossRef]

37. Guevara-Campos, J.; Gonzalez-Guevara, L.; Puig-Alcaraz, C.; Cauli, O. Autism spectrum disorders associated to a deficiency of the enzymes of the mitochondrial respiratory chain. Metab. Brain Dis. 2013, 28, 605-612. [CrossRef]

38. Palmieri, L.; Papaleo, V.; Porcelli, V.; Scarcia, P.; Gaita, L.; Sacco, R.; Hager, J.; Rousseau, F.; Curatolo, P.; Manzi, B.; et al Altered calcium homeostasis in autism-spectrum disorders: Evidence from biochemical and genetic studies of the mitochondrial aspartate/glutamate carrier agc1. Mol. Psychiatry 2010, 15, 38-52. [CrossRef]

39. Frye, R.E.; Naviaux, R.K. Autistic disorder with complex iv overactivity: A new mitochondrial syndrome. J. Pediatr. Neurol. 2011, 9, 427-434.

40. Chauhan, A.; Essa, M.M.; Merz, G.; Muthaiyah, B.; Ted Brown, W.; Chauhan, V. 81 mitochondrial abnormalities in lymphoblasts from autism. Mitochondrion 2010, 10, 223. [CrossRef]

41. James, S.J.; Rose, S.; Melnyk, S.; Jernigan, S.; Blossom, S.; Pavliv, O.; Gaylor, D.W. Cellular and mitochondrial glutathione redox imbalance in lymphoblastoid cells derived from children with autism. FASEB J. 2009, 23, 2374-2383. [CrossRef] [PubMed]

42. Zorova, L.D.; Popkov, V.A.; Plotnikov, E.Y.; Silachev, D.N.; Pevzner, I.B.; Jankauskas, S.S.; Babenko, V.A.; Zorov, S.D.; Balakireva, A.V.; Juhaszova, M.; et al. Mitochondrial membrane potential. Anal. Biochem. 2018, 552, 50-59. [CrossRef] [PubMed] 
43. Suski, J.M.; Lebiedzinska, M.; Bonora, M.; Pinton, P.; Duszynski, J.; Wieckowski, M.R. Relation between mitochondrial membrane potential and ros formation. Methods Mol. Biol. 2012, 810, 183-205. [PubMed]

44. Korshunov, S.S.; Skulachev, V.P.; Starkov, A.A. High protonic potential actuates a mechanism of production of reactive oxygen species in mitochondria. FEBS Lett. 1997, 416, 15-18. [CrossRef]

45. Skulachev, V.P. Role of uncoupled and non-coupled oxidations in maintenance of safely low levels of oxygen and its one-electron reductants. Q. Rev. Biophys. 1996, 29, 169-202. [CrossRef] 